\title{
Effects of the human antiepileptic drug carbamazepine on the behavior, biomarkers, and heat shock proteins in the Asian clam Corbicula fluminea
}

\author{
Huihui Chen, Jinmiao Zha*, Xuefang Liang, Jiasu Li, Zijian Wang* \\ State Key Laboratory of Environmental Aquatic Chemistry, Research Center for Eco-Environmental Sciences, Chinese Academy of Sciences, \\ Shuangqing Rd 18, Haidian District, PO Box 2871, Beijing 100085, PR China
}

\section{A R T I C L E I N F O}

\section{Article history:}

Received 30 March 2014

Received in revised form 28 May 2014

Accepted 2 June 2014

Available online 9 June 2014

\section{Keywords:}

Carbamazepine

Corbicula fluminea

Siphoning behavior

Antioxidant enzymes

Heat shock proteins

\begin{abstract}
A B S T R A C T
Carbamazepine (CBZ), an anticonvulsant and mood-stabilizing pharmaceutical, is a widespread contaminant in aquatic environments. In this study, the effects of chronic exposure to environmentally relevant $\mathrm{CBZ}$ concentrations were investigated in freshwater clams Corbicula fluminea. Adult $C$. fluminea were exposed to $0.5,5$, and $50 \mu \mathrm{g} / \mathrm{L}$ of CBZ for 30 days, after which siphoning behavior (filtration rates), biomarker levels, and heat shock protein expression were measured. The filtration rates were significantly decreased $(p<0.05)$ by $50 \mu \mathrm{g} / \mathrm{L} \mathrm{CBZ}$ treatment, indicating a negative impact on $C$. fluminea health. Superoxide dismutase (SOD) and glutathione reductase (GR) activities were decreased, and catalase (CAT) activity and malondialdehyde (MDA) content were increased in the gills and digestive gland, suggesting that CBZ induced an oxidative effect. The levels of Hsp22, Hsp40, and Hsp70 mRNAs were also markedly induced after 5 or $50 \mu \mathrm{g} / \mathrm{L} \mathrm{CBZ}$ treatment ( $p<0.05$ ), whereas Hsp60 and Hsp90 mRNAs in gills and Hsp60 mRNA in digestive gland were significantly repressed $(p<0.05)$. Finally, the expression of Hsp70 protein was significantly increased $(p<0.05)$ by 5 and $50 \mu \mathrm{g} / \mathrm{L}$ exposure. In aggregate, these results confirm that environmentally relevant concentrations of $\mathrm{CBZ}$ can exert a negative effect on $C$. fluminea tissue at the molecular and protein level.
\end{abstract}

(C) 2014 Elsevier B.V. All rights reserved.

\section{Introduction}

In the last years, a large and diverse collection of bioactive pharmaceutical chemicals are being used in human and veterinary medicine and in livestock farming (Kim et al., 2007). Recent studies have to document the presence of pharmaceuticals (i.e., hormonal, antiepileptic and neuroactive drugs) at the $\mathrm{ng} / \mathrm{L}$ to $\mu \mathrm{g} / \mathrm{L}$ in sewage treatment plant (STP) effluents, surface waters, groundwater, and even in drinking water sources (Daughton and Ternes, 1999; Fent et al., 2006; Blair et al., 2013; Daughton, 2014; Liu and Wong, 2013). The ecotoxicological risk that this contamination poses to non-target organisms however is still scarce (Fent et al., 2006; Gonzalez-Rey and Bebianno, 2013).

\footnotetext{
* Corresponding authors at: Research Center for Eco-Environmental Sciences, Chinese Academy of Sciences, State Key Laboratory of Environmental Aquatic Chemistry, Shuangqing Rd 18, Haidian District, Beijing 100085, PR China. Tel.: +86 10 62849107; fax: +861062849140 (J. Zha). Tel./fax: +861062849140 (Z. Wang).

E-mail addresses: jmzha@rcees.ac.cn, jinmiaozha@gmail.com (J. Zha), zjwang@rcees.ac.cn (Z. Wang).
}

One heavily used pharmaceutical, carbamazepine (CBZ), is an anticonvulsant and mood-stabilizing drug used primarily for treating epilepsy and bipolar disorder, as well as trigeminal neuralgia (García-Morales et al., 2007). CBZ is not easily removed from waste streams by conventional waste water treatment plants (WWTP), with a removal efficiency of less than $10 \%$ (Zhang et al., 2008). Consequently, significant levels of CBZ are steadily discharged into receiving water bodies (Liu and Wong, 2013), and CBZ contamination has been widely documented in WWTP influents and effluents, surface water, and even drinking water (Fent et al., 2006). In fact, a recent study reported CBZ contamination in $95 \%$ of water samples collected from various locations throughout the USA, at an average concentration of $350 \mathrm{ng} / \mathrm{L}$ (Ferrer and Thurman, 2012). CBZ contamination has also been documented in WWTP influents and effluents in Shanghai, China, at concentrations ranging from 230 to $1110 \mathrm{ng} / \mathrm{L}$ and in the Yangtze River at concentrations up to $1090 \mathrm{ng} / \mathrm{L}$ (Liu and Wong, 2013).

Previous studies have reported that CBZ can induce chronic effects in non-target organisms at relevant environmental concentrations (Ferrari et al., 2004; Martin-Diaz et al., 2009; Contardo-Jara et al., 2011; Tsiaka et al., 2013). For example, Martin-Diaz et al. (2009) reported that CBZ exposure $(0.1$ and $10 \mu \mathrm{g} / \mathrm{L})$ influenced the 
antioxidant enzyme system, cAMP pathway, and the mitoxantrone resistance protein (MXR) system in mussels (Mytilus galloprovincialis). Similarly, exposure to 100 or $1000 \mathrm{nM} \mathrm{CBZ}$ repressed the levels of heat shock protein 70 (Hsp70) and superoxide dismutase (SOD) mRNA in the gills and metallothionein (MT) and $P$-glycoprotein $(P$-gp) in the digestive gland of zebra mussels (Dreissena polymorpha) (Contardo-Jara et al., 2011). In another study, Tsiaka et al. (2013) found that $0.01-100 \mu \mathrm{g} / \mathrm{L} \mathrm{CBZ}$ exposure was cytotoxic to $M$. galloprovincialis cells in vitro and increased cellular superoxide anions and nitric oxide. These results all suggest that CBZ can significantly affect multiple oxidative and biochemical pathways in bivalves, with significant deleterious effects. Even so, neither the mechanism of CBZ action nor the behavioral effects of $\mathrm{CBZ}$ on aquatic organisms have been well investigated.

In this study, we sought to determine the toxic effects of $\mathrm{CBZ}$ on a freshwater bivalve (Corbicula fluminea) by measuring multiple toxicological endpoints considering environmentally relevant concentrations. C. fluminea is commonly known as the Asian clam and is native to Southeast Asia (Araujo et al., 1993). As a benthonic freshwater bivalve, $C$. fluminea has been commonly used in field and laboratory studies to measure environmental perturbations or contaminations (Vasconcelos et al., 2009; Chen et al., 2013; Ren et al., 2013). In the present study, adult $C$. fluminea were exposed to $\mathrm{CBZ}$ for 30 days, after which multi-endpoints were measured, including siphoning behavior, the levels of four stress biomarkers: SOD, catalase (CAT), glucocorticoid receptor (GR), and malondialdehyde (MDA), and the expression of heat shock protein mRNAs in gills and digestive gland. The fluctuation of antioxidant enzymes and heat shock proteins have been used successfully as oxidative stress and early-warning bio-indicators of cellular hazards in bivalves species (Contardo-Jara et al., 2011; GonzalezRey and Bebianno, 2013; Gupta et al., 2010). Moreover, since the Hsp70 is the most general biomarker used for cellular stress and more highly conserved across taxa (Del Rey et al., 2011; Gupta et al., 2010), the protein expressions of Hsp70 in gills and digestive gland were also determined. The possible mechanism of CBZ action on aquatic organisms was examined based on the toxicological findings.

\section{Materials and methods}

\subsection{Chemicals}

Carbamazepine (CAS: 298-46-4, purity >97\%) was purchased from J\&K Chemical Ltd. (USA). CBZ stock solutions were prepared in dimethylsulfoxide (DMSO) and stored in brown bottles.

\subsection{Clams}

C. fluminea (average length of $20.56 \pm 2.05 \mathrm{~mm}$ ) were collected from natural populations in Hongzehu Lake, China, and were transferred to the laboratory in fish tanks with continuous aeration. Once in the lab, they were housed in 50-L glass aquaria (30 individuals per aquarium) filled with aerated natural water maintained at a constant temperature $\left(20 \pm 1^{\circ} \mathrm{C}\right), \mathrm{pH}(7.8 \pm 0.2)$, and oxygen saturation $(96 \% \pm 2 \%)$. Photoperiod was set at $12: 12$ h (light:dark). The clams were fed single-celled Chlorella vulgaris and Scenedesmus obliquus algae daily.

\subsection{CBZ exposure assay}

The clams were acclimated to the exposure aquarium (10 L containing $8 \mathrm{~L}$ aerated natural water) for 7 days before initiate of the experiment. Then, the clams were randomly distributed into five experimental groups, each group contained three replicate aquariums and each replicate aquarium included 20 clams. Nutrition, water, temperature and light conditions were maintained constant during the time of acclimatization and exposure. After the acclimatization, the clams were exposed for 30 days to dilutions of a CBZ/DMSO solution that provided final CBZ concentrations of $0.5,5$, or $50 \mu \mathrm{g} / \mathrm{L}(2.12,21.2$ or $212 \mathrm{nM})$. Final DMSO concentration was $0.001 \%(\mathrm{w} / \mathrm{v})$ in the $\mathrm{CBZ}$ exposure groups. A group containing aerated natural water was used as control, and a treatment with $0.001 \%(w / v)$ DMSO was served as solvent control. All control or treated groups were in triplicate. The water and CBZ or DMSO was refreshed daily.

The mortality for all groups was recorded throughout the 30-day exposure period, and the gills and digestive gland were collected at the end of the study and stored individually at $-80^{\circ} \mathrm{C}$ for future analyses. At least three independent biological replicates were harvested for each treatment group. The clams in the control groups were immediately analyzed for biomarkers to assess their initial health status, and the results were not significantly different from those of clams exposed to the solvent control (0.001\% DMSO) for 30 days (data not shown). A condition index $(\mathrm{CI})$ was calculated based on individual weights of $10 \mathrm{C}$. fluminea from each group as follows (Gonzalez-Rey and Bebianno, 2013):

$\mathrm{CI}(\%)=\frac{W_{s}}{W_{t}} \times 100$,

where $W_{s}$ is the wet weight of the entire soft tissue, and $W_{t}$ is the wet weight of the entire body, including the shell.

\subsection{Water concentrations of $C B Z$}

CBZ concentrations were quantified immediately after tanks were dosed each week using ultra-performance liquid chromatography tandem mass spectrometry (UPLC-MS/MS) according to a previously described method (Batt et al., 2008). Briefly, water samples were filtered through a $0.2-\mu \mathrm{m}$ GH Polypro membrane filter (PALL, New York, USA) to remove any suspended matter and injected onto a Waters Acquity UPLC fitted with a BEH C18 column $(50 \times 2.1 \mathrm{~mm}, 1.7 \mu \mathrm{m}$; Waters, Milford, MA, USA) maintained at $30^{\circ} \mathrm{C}$. A tandem Quattro Premier XE mass spectrometer (Waters, Milford, MA, USA) equipped with an electrospray ionization (ESI) ion source was used for CBZ detection, with all measurements taken in positive ESI mode. Multiple reaction monitoring (MRM) transitions were 237.1>194.2 (quantification) and 237.1 >179.2 (confirmation), respectively. External standard solutions of CBZ were used to determine precise concentrations in test samples. The limit of detection and limit of quantification for the method were 0.01 and $0.02 \mu \mathrm{g} / \mathrm{L}$, respectively. The actual determined CBZ concentrations (mean \pm standard deviation; and \% analyzed/nominal) during the exposure period were $0.45 \pm 0.13 \mu \mathrm{g} / \mathrm{L}$ (90\%) for the $0.5 \mu \mathrm{g} / \mathrm{L}$ treatments, $4.62 \pm 0.88 \mu \mathrm{g} / \mathrm{L}$ (92\%) for the $5 \mu \mathrm{g} / \mathrm{L}$ treatments, and $43.76 \pm 2.35 \mu \mathrm{g} / \mathrm{L}$ (87\%) for the $50 \mu \mathrm{g} / \mathrm{L}$ treatments. The nominal CBZ values are used throughout the remaining text.

\subsection{Siphoning behavior}

The siphoning rate was measured using a previously described method (Cooper and Bidwell, 2006) with slight modifications and is based on depletion of neutral red dye particles from the water due to filtration by the clams. Immediately after CBZ exposure, five C. fluminea from each CBZ concentration group and control group were placed in $200-\mathrm{mL}$ beakers that contained $100 \mathrm{~mL}$ of a neutral red solution $(1 \mathrm{mg} / \mathrm{L}$ in dechlorinated tap water with no added $\mathrm{CBZ}$ ) and were allowed to siphon for $2 \mathrm{~h}$. Just prior to placing the $C$. fluminea in the solution and just after the $2 \mathrm{~h}$ siphoning period, 1 $\mathrm{mL}$ aliquots of the water were removed from each beaker, and the 
neutral red concentration was determined by measuring the optical density at $530 \mathrm{~nm}$ using a spectrophotometer. Standard solutions of neutral red were used to generate a standard curve from which the dye concentrations in each test sample were calculated using the equation of Cooper and Bidwell (2006):

$m=\left[\frac{M}{n t}\right] \log \left(\frac{C_{0}}{C_{t}}\right)$,

where $M$ is the volume of the test solution, $n$ is the number of clams used, $t$ is the time in hours, $C_{0}$ is the initial concentration of the dye, $C_{t}$ is the concentration of the dye at time $t$, and $m$ is the filtration rate $(\mathrm{mL} / \mathrm{animal} / \mathrm{h})$.

\subsection{Tissue preparation for biomarker and western blot analysis}

Approximately $200 \mathrm{mg}$ of each tissue sample was ground with a pestle in a $1-\mathrm{mL}$ centrifuge tube in the presence of $0.5 \mathrm{~mL}$ radioimmunoprecipitation assay lysis buffer (Beyotime, China) on ice. The resulting homogenate was centrifuged at $11,000 \times \mathrm{g}$ for $10 \mathrm{~min}$, and the supernatant was collected into a new $1.5-\mathrm{mL}$ tube. The protein content of the supernatant was determined using a BCA Protein Assay Kit (Beyotime, China), and the samples were frozen at $-80^{\circ} \mathrm{C}$ until further analysis.

\subsection{Biomarker measurements}

The activities of SOD, CAT, and GR were analyzed in gills and digestive gland tissue samples. An aliquot of $20 \mu \mathrm{L}$ supernatant from each tissue sample was used for each of the biomarker assays. SOD activity was determined using a SOD Assay Analysis Kit (Beyotime, China) according to the manufacturer's protocol, which is based on the method of McCord and Fridovich (1969). The SOD activity is expressed in units (U) per minute per mg protein. CAT activity was measured by monitoring the decrease in absorbance of hydrogen peroxide $\left(\mathrm{H}_{2} \mathrm{O}_{2}\right)$ at $240 \mathrm{~nm}$, with units of $\mathrm{U} / \mathrm{mg}$ protein. A value of $1 \mathrm{U}$ CAT activity was defined as $1 \mu \mathrm{mol} \mathrm{H}_{2} \mathrm{O}_{2}$ consumption per min at $25^{\circ} \mathrm{C}$ and $\mathrm{pH}$ 7.0. GR activity was measured using a Glutathione Reductase Assay Kit (Beyotime, China). One unit of GR activity was defined as the reduction of $1 \mu \mathrm{mol}$ of oxidized glutathione (GSSG) at $25^{\circ} \mathrm{C}, \mathrm{pH} 7.0$, and GR activity is expressed as $\mathrm{U} / \mathrm{mg}$ protein. MDA content was measured using a Lipid Peroxidation MDA Assay Kit (Beyotime, China) that relies on detecting thiobarbituric acid adduction to MDA. Precise concentrations were determined by comparison with a standard curve generated with prepared MDA standards. MDA concentrations are expressed as nmol/mg mg protein.

\section{8. $q R T-P C R$}

Total RNA was isolated from gill and digestive gland tissue samples by means of an SV Total RNA Isolation System (Promega, USA) according to the manufacturer's protocols. The mRNA expression was measured using an ABI 7500 real-time quantitative PCR system (Life Technology, USA) according to a method reported in a previous study (Chen et al., 2013). The sequences and PCR product sizes for each primer pair are shown in Table 1 . The results were analyzed based on the $2^{-\Delta \Delta C t}$ method (Schmittgen and Livak, 2008), with all experiments performed three times in triplicate, with similar results.

\subsection{Electrophoresis and immunochemical assay of Hsp70 protein}

The protein samples were dissolved in a sodium dodecyl sulfate (SDS) sample buffer at a concentration of $5 \mu \mathrm{g} / \mu \mathrm{L}$ and boiled for $5 \mathrm{~min}$. Aliquots corresponding to $50 \mu \mathrm{g}$ total protein were analyzed by SDS-polyacrylamide gel electrophoresis (5\% stacking and $10 \%$ separating) for $2 \mathrm{~h}$ at $80 \mathrm{~V}$. After electrophoresis, the proteins were transferred to a nitrocellulose membrane via wet blotting ( $100 \mathrm{~mA}$ for $50 \mathrm{~min}$ ), after which non-specific binding sites were blocked by immersing the membrane in TBST $(0.02 \mathrm{M}$ Tris-HCL, $0.5 \mathrm{M} \mathrm{NaCl}$ with $0.05 \%$ Tween-20, pH 7.5) that contained $5 \%$ non-fat dry milk for $1 \mathrm{~h}$ at $25^{\circ} \mathrm{C}$. The membrane was then rinsed with TBST for $10 \mathrm{~min}$ and incubated at $4{ }^{\circ} \mathrm{C}$ overnight in the presence of rabbit anti-Hsp70 (1:200 dilution, HSP70 (K-20)-R, Santa Cruz Biotechnology, USA) and rabbit anti- $\beta$-actin (1:1000 dilution, Cell Signaling Technology, Inc., USA) antibodies. The blots were washed twice with TBST for $10 \mathrm{~min}$ and once with TBS for $10 \mathrm{~min}$, and the blots were then incubated with a second antibody ( $1: 1000$ dilutions, goat anti-rabbit IgG-HRP: sc-2004, Santa Cruz Biotechnology, USA) for $1 \mathrm{~h}$ at $28^{\circ} \mathrm{C}$. After incubation, the bands were washed as in the previous step and visualized using an Enhanced Chemiluminescence (ECL) detection reagent kit (Beyotime, China), with the band optical densities quantified using VisionWorksLS Image Acquisition and Analysis Software 7.1 (UVP, USA). Relative optical densities were obtained by normalizing each band against the standard band from control clams.

\subsection{Statistical analysis}

All statistical analyses were performed using SPSS (version 16.0) and OriginPro (version 8.0) software. The experimental data were checked for homogeneity of variance by using Levene's test. All quantitative data are expressed as the mean \pm standard error of the mean (SEM). The significance of the differences between exposed and control samples was determined using a one-way ANOVA $(p<0.05)$ followed by Dunnett's test for multiple comparisons.

Table 1

Primer sequences used in Corbicula fluminea.

\begin{tabular}{|c|c|c|c|c|c|}
\hline Genes & Genes (accession no.) & Realtime-PCR primer sequence $\left(5^{\prime}-3^{\prime}\right)$ & $\begin{array}{l}\text { Product size } \\
\text { (bp) }\end{array}$ & $\begin{array}{l}\text { Annealing } \\
\text { temperatures }\left({ }^{\circ} \mathrm{C}\right)\end{array}$ & $\begin{array}{l}\text { PCR efficiency } \\
(\%)\end{array}$ \\
\hline \multirow[t]{2}{*}{$\beta$-actin } & EF446608.1 & F:CGCCATCCAGGCTGTGCTTTCA & 123 & 55.0 & 97.0 \\
\hline & & R:ATGGCGTGTGGAAGGGCGTA & & & \\
\hline \multirow[t]{2}{*}{ Hsp22 } & KF218338 & F:CTTTCAACCTGGAGCATTGTG & 154 & 57.0 & 96.1 \\
\hline & & R:CGTGATTTGTTTTCGGACTG & & & \\
\hline \multirow[t]{2}{*}{ Hsp40 } & KF218339 & F:ACAAGCAGCATCCCAGATTCC & 82 & 56.5 & 99.9 \\
\hline & & R:TCCAGTCAGAGCCTTTCCCA & & & \\
\hline \multirow[t]{2}{*}{ Hsp60 } & КС979065 & F:GGGACAACAGAAAGAACACCC & 120 & 55.0 & 97.9 \\
\hline & & R:CCGACACGACCAAAGTCATT & & & \\
\hline \multirow[t]{2}{*}{ Hsp70 } & КС979064 & F:CGCCGACGCTGATTACCTTA & 84 & 55.0 & 95.6 \\
\hline & & R:AAACGGTTGATAGGACGCAAG & & & \\
\hline \multirow[t]{2}{*}{ Hsp90 } & КС979063 & F:ATGGTGCTGGAATCTCTCAGG & 246 & 55.0 & 101.6 \\
\hline & & R:GCGTCACAAAGGAAGGACTG & & & \\
\hline
\end{tabular}




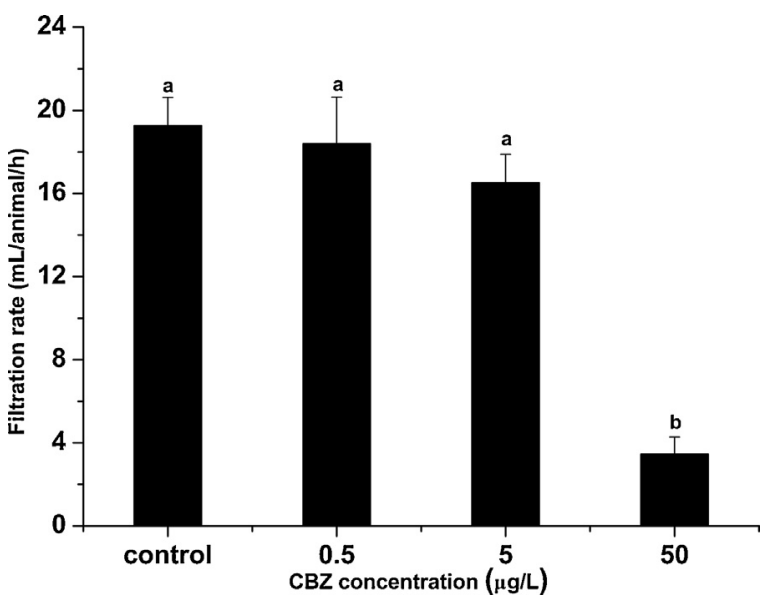

Fig. 1. Average $(n=5)$ filtration rate $(\mathrm{mL} / \mathrm{animal} / \mathrm{h})$ of $C$. fluminea in CBZcontaminated water containing $1 \mathrm{mg} / \mathrm{L}$ neutral red solution following exposure to the indicated concentrations. The experiments were performed in triplicate and repeated three times with similar results. The bars display the mean $\pm \mathrm{SEM}$. A statistically significant difference between treatment group and control $(p<0.05, n=5$, ANOVA) is indicated by differences in the letters above the bars.

\section{Results}

\subsection{Mortality and condition index (CI)}

Over the course of the 30-day exposure to various CBZ concentrations, less than $3 \%$ mortality was observed at all CBZ concentrations (data not shown). Likewise, the CI was not significantly different among the treatments and the control (range from $32.8 \%$ to $39.2 \%$, data not shown).

\subsection{CBZ effects on siphoning behavior}

There was no statistical difference observed in the siphoning behavior among the control and low concentration CBZ treatments $(0.5$ and $5 \mu \mathrm{g} / \mathrm{L})$. The filtration rates of individual clams among these groups ranged from 16.52 to $19.62 \mathrm{~mL} / \mathrm{animal} / \mathrm{h}$. However, the filtration rate at $50 \mu \mathrm{g} / \mathrm{L} \mathrm{CBZ}(3.45 \pm 0.82 \mathrm{~mL} / \mathrm{animal} / \mathrm{h})$ was significantly decreased compared to the control group $(19.27 \pm 1.36 \mathrm{~mL} /$ animal $/ \mathrm{h})(p<0.05$; Fig. 1$)$.

\subsection{CBZ effects on biomarkers}

The activities of SOD, CAT, and GR and the MDA content were measured in gill and digestive gland tissue isolated from all treatment groups. The SOD activity was higher in gills than in the digestive gland for all control and CBZ exposure groups (Fig. 2A and $B)$. In the gills, SOD activity was significantly inhibited by $50 \mu \mathrm{g} / \mathrm{L}$ CBZ exposure compared to the control group ( $p<0.05$; Fig. $2 \mathrm{~A}$ ); no significant differences were observed at the 0.5 and $5 \mu \mathrm{g} / \mathrm{L}$ groups. In the digestive gland, inhibition of SOD activity was observed in both the 5 and $50 \mu \mathrm{g} / \mathrm{L} \mathrm{CBZ}$ exposure groups compared to the control group $(p<0.05$; Fig. $2 \mathrm{~B})$. In contrast to the SOD activity measurements, CAT activity was higher in digestive gland than in gills (Fig. 2C and D). Moreover, CAT activity was significantly upregulated by all concentrations of $C B Z$ in both the gills and in the digestive gland ( $p<0.05$; Fig. $2 C$ ). The GR activity was significantly decreased in the gills by all three CBZ concentrations $(p<0.05$; Fig. 2E). No significant changes in GR activity were observed in the digestive gland in the $0.5 \mu \mathrm{g} / \mathrm{L}$ CBZ treatment, whereas significant down-regulation was observed after 5 and $50 \mu \mathrm{g} / \mathrm{L} \mathrm{CBZ} \mathrm{exposure}$ (Fig. 2F). Finally, MDA was significantly up-regulated in the gills by 5 and $50 \mu \mathrm{g} / \mathrm{L} \mathrm{CBZ}$ and in the digestive gland by $50 \mu \mathrm{g} / \mathrm{L} \mathrm{CBZ}$ $(p<0.05$; Fig. 2G and H). No significant differences in MDA levels were observed in either tissue type after $0.5 \mu \mathrm{g} / \mathrm{L} \mathrm{CBZ}$ exposure (Fig. 2G and $\mathrm{H}$ ).

\subsection{CBZ effects on Hsp gene expression}

The mRNA expression levels of five Hsp genes (Hsp22, Hsp40, $H s p 60, H s p 70$, and Hsp90) in the gills and digestive gland were evaluated after CBZ exposure (Fig. 3). In the gills, expression of Hsp22, $H s p 40$, and $H s p 70$ transcripts was significantly increased (3.81-fold, 14.81-fold, and 3.52-fold, respectively) by 5 and $50 \mu \mathrm{g} / \mathrm{L} \mathrm{CBZ} \mathrm{expo-}$ sure compared to controls $(p<0.05)$, with the greatest increase observed after $50 \mu \mathrm{g} / \mathrm{L} \mathrm{CBZ} \mathrm{exposure} \mathrm{(Fig.} \mathrm{3A,} \mathrm{C} \mathrm{and} \mathrm{G).} \mathrm{In} \mathrm{contrast,}$ the expression of $H s p 60$ and $H s p 90$ was repressed in the gills after 5 and $50 \mu \mathrm{g} / \mathrm{L} \mathrm{CBZ} \mathrm{exposure} \mathrm{(} p<0.05$ ), with the greatest inhibition observed in the $50 \mu \mathrm{g} / \mathrm{L} \mathrm{CBZ}$ group (0.47- and 0.18-fold for Hsp60 and $H s p 90$, respectively; Fig. $3 \mathrm{E}$ and I).

In the digestive gland, the expression of Hsp22, Hsp40, Hsp70, and $H s p 90$ transcripts was significantly increased after 5 and $50 \mu \mathrm{g} / \mathrm{L} \mathrm{CBZ} \mathrm{exposure} \mathrm{(} p<0.05$ ) as follows: Hsp22, 4.74-fold; Hsp40, 16.73-fold; Hsp70, 8.47-fold; and Hsp90, 8.21-fold; Fig. 3). In addition, $H s p 60$ mRNA level was significantly decreased in the digestive gland after 5 and $50 \mu \mathrm{g} / \mathrm{L}$ CBZ exposure ( $p<0.05$; Fig. 3F).

\subsection{CBZ effects on Hsp70 protein expression}

The protein expression of Hsp70 was also determined by western blotting. Exposure to 5 or $50 \mu \mathrm{g} / \mathrm{L} \mathrm{CBZ} \mathrm{significantly} \mathrm{increased}$ Hsp70 protein levels in both the gills and the digestive gland $(p<0.05$; Fig. $4 \mathrm{~A}$ and B). The largest increase was observed in the $50 \mu \mathrm{g} / \mathrm{L}$ CBZ exposure group, with a 2.36-fold increase in the gills and a 3.37-fold increase in the digestive gland $(p<0.05$; Fig. $4 \mathrm{~A}$ and B).

\section{Discussion}

C. fluminea lives in the sediment of waterways and filters suspended materials and colloids from large volumes of water. As such, it is a useful indicator species for assessing the toxicity of water contaminants (Vasconcelos et al., 2009). In the present study, we used $C$. fluminea to assess the effects of chronic exposure to CBZ by evaluating siphoning behavior, biomarkers, transcripts levels of Hsp genes, and the expression of Hsp70 protein in the gills and digestive gland.

Siphoning behavior and valve movement have both been utilized as indicators for continuous biomonitoring of water supplies and effluents (Chen et al., 2012). Bivalve siphons play important functional roles in nutritional physiology, defense, and reproduction (Moulton et al., 1996) and are therefore a signal of general health or stress. In fact, previous studies have demonstrated that bivalve siphoning can be influenced by metals or chlorpyrifos (Doherty et al., 1987; Milam and Farris, 1998; Cooper and Bidwell, 2006). Cooper and Bidwell (2006) reported that the valves of the clams were always closed during exposure to $3.13 \mathrm{mg} / \mathrm{L}$ chlorpyrifos treatments. A reduction in siphoning activity as a response to chemical stress has also been associated with ammonia accumulation in the tissue, a reduction in oxygen exchange, and reduced feeding (Moulton et al., 1996). Herein, we found that CBZ exposure decreased the filtration rates of clams, although no significant valve closure was observed. It is therefore reasonable to conclude that the decreased siphoning caused by CBZ exposure reflects an overall negative health impact and an indicator of chemical stress.

The effects of pollutants are often manifested as imbalances in antioxidant and fatty acid metabolism systems (Koehler, 2004). Previous studies have shown that exposure to CBZ, ibuprofen, or 
(A)

(C)
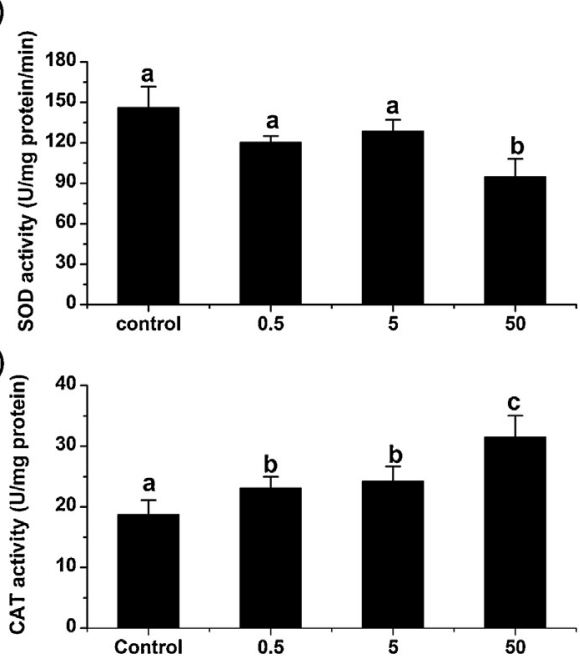

$(\mathrm{E})$

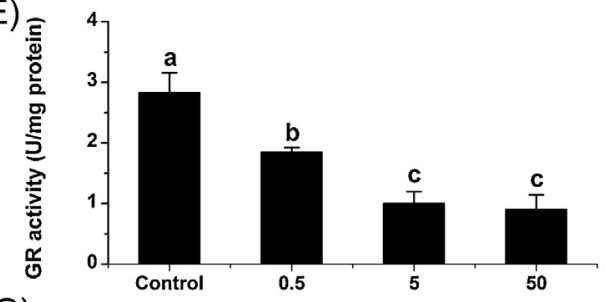

(G)

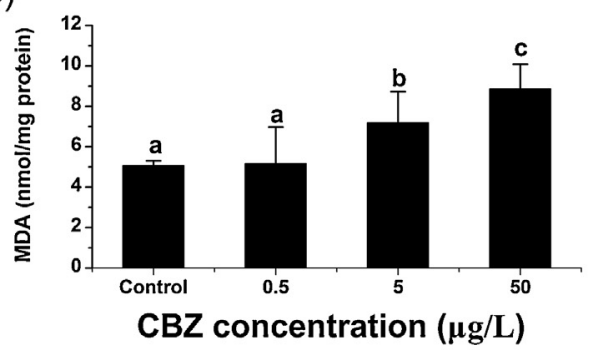

(B)

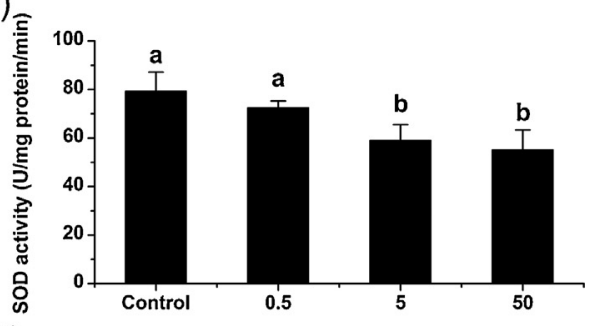

(D)

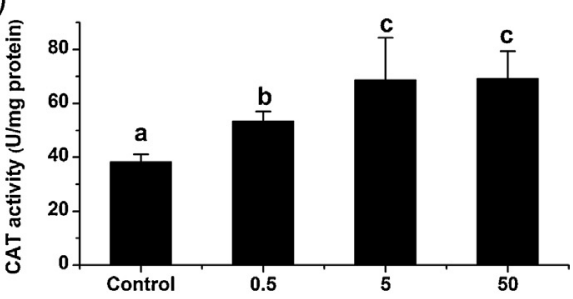

(F)

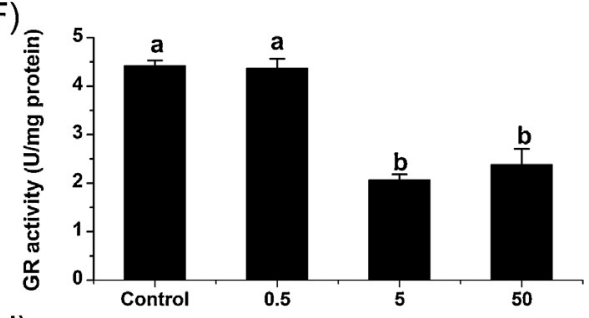

$(\mathrm{H})$

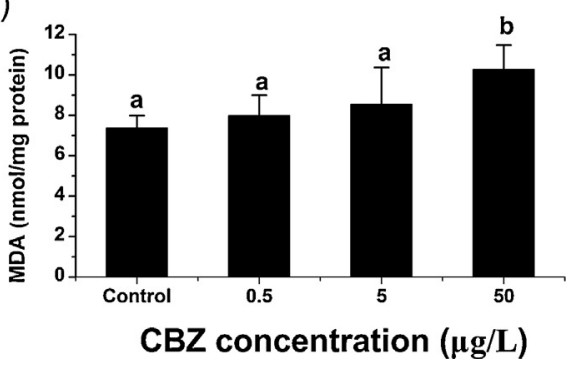

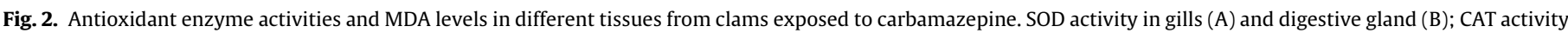

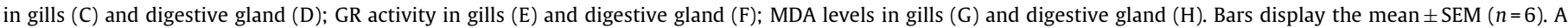
statistically significant difference between treatment groups and control $(p<0.05, n=6$, ANOVA) is indicated by differences in the letters above the bars.

bezafibrate pharmaceuticals induced oxidative effects in the zebra mussel D. polymorpha (Contardo-Jara et al., 2011). Consistent with this, CBZ exposure significantly decreased SOD and GR activity and increased CAT activity in the gills and digestive gland of $C$. fluminea. These results indicate that environmentally relevant concentrations of CBZ enhanced the production of reactive oxygen species (ROS) in C. fluminea. It is most likely that an increase in superoxide anions stimulated the consumption of SOD, and that CAT activity was induced by $\mathrm{H}_{2} \mathrm{O}_{2}$ formation (Ren et al., 2013). The observed decrease in GR activity may also indicate increased ROS levels, since the role of GR is to regenerate the antioxidant glutathione from GSSG (Verlecar et al., 2008).

MDA levels were also significantly increased in the gills and digestive gland by exposure to higher CBZ concentrations, which further supports the notion of an increase in ROS. MDA is produced from the decomposition of unsaturated fatty acid peroxides that are generated by and rapidly degraded by ROS (Marnett, 1999; Stancliffe et al., 2011). Thus, if the ROS content exceeded the elimination capacity of antioxidant enzymes, the excess ROS could stimulate MDA production (Lushchak, 2011). A similar result was reported by Ren et al. (2013), in that cadmium exposure reduced SOD activity and enhanced CAT and MDA in the digestive gland of
C. fluminea (Ren et al., 2013). Moreover, Martin-Diaz et al. (2009) reported that 0.1 and $10 \mu \mathrm{g} / \mathrm{L} \mathrm{CBZ}$ exposure induced CAT activity in the digestive gland and MDA content in the gills of M. galloprovincialis. Finally, an in vitro study with $M$. galloprovincialis cells revealed an increase in MDA content after 0.01-100 $\mu \mathrm{g} / \mathrm{L}$ CBZ exposure (Tsiaka et al., 2013). Thus, previously reported results and our findings all indicate that $\mathrm{CBZ}$ can induce oxidative stress in bivalve species.

Heat shock proteins are also suitable early-warning bioindicators of cellular hazards due to their sensitivity to even minor assaults (Santoro, 2000; Sørensen et al., 2003; Gupta et al., 2010). Previous studies have reported that various stressors (e.g., temperature, metal toxicity and infection) affect the expression of Hsp60, Hsp70, and Hsp90 transcript and protein levels (Luchmann et al., 2011; Liu et al., 2012; Zhang and Zhang, 2012; Jing et al., 2013). Likewise, Kim et al. (2011) reported that low doses of UV-B radiation (2 and $4 \mathrm{~kJ} / \mathrm{m}^{2}$ ) increased the expression of Hsp10, Hsp20, and Hsp27 mRNAs in Brachionus rotifers. Herein, we evaluated the effect of CBZ exposure on five Hsps, including Hsp22 and Hsp40, which belong to the heterologous sHsp family of 12-43 kDa Hsps (Hull et al., 2013). Hsp22 is a recently identified member of the small heat shock protein superfamily that can interact with mimics of phosphorylated 
(A)

(C)
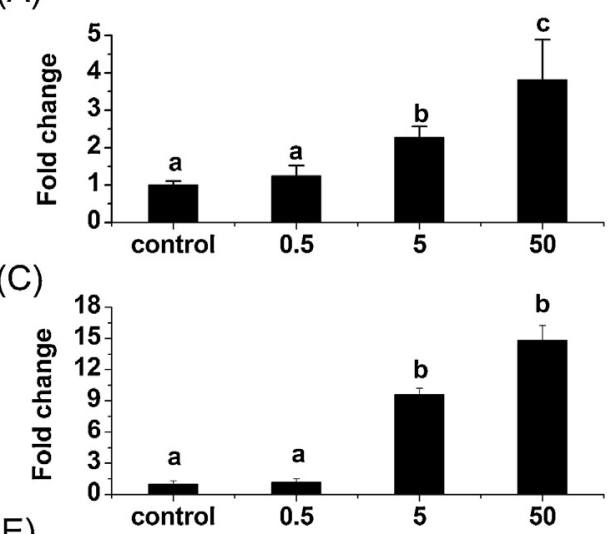

(E)

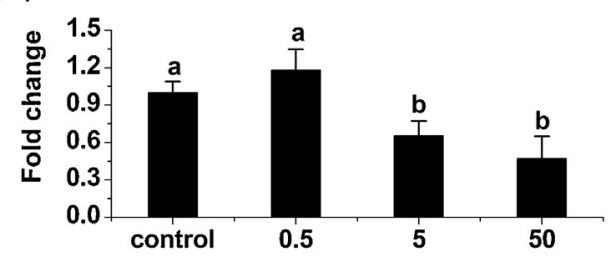

(G)

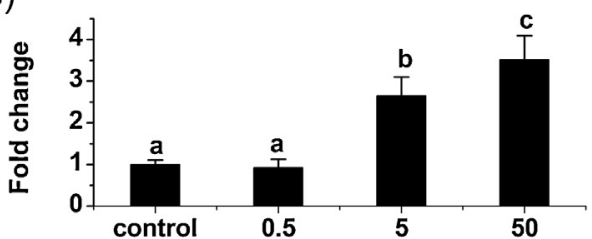

(I)

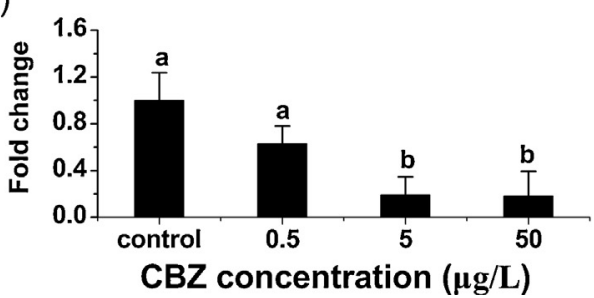

(B)

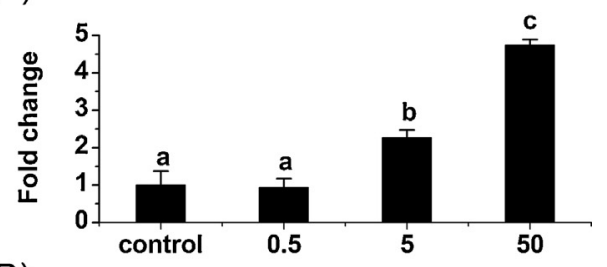

(D)

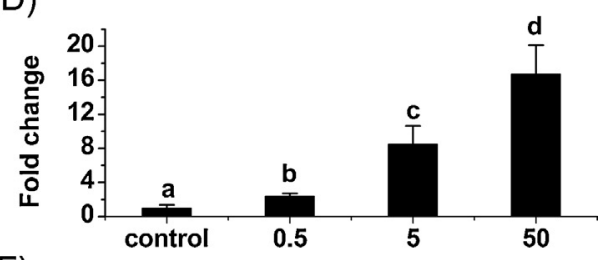

$(\mathrm{F})$

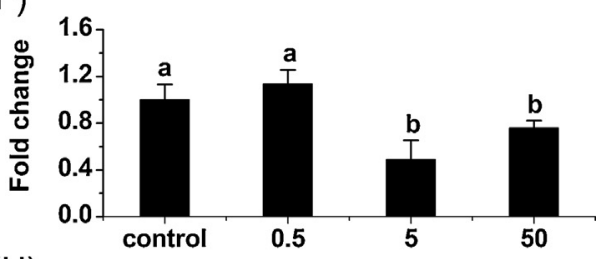

(H)

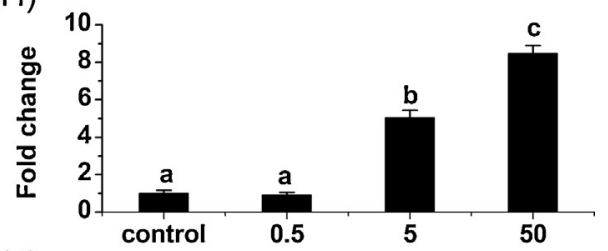

(J)

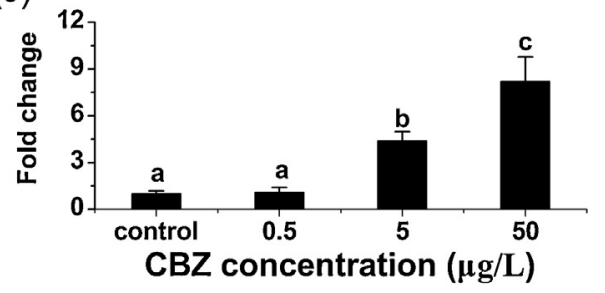

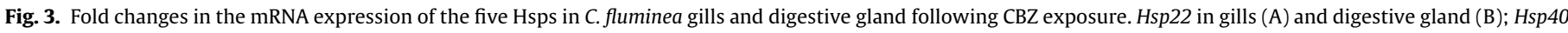

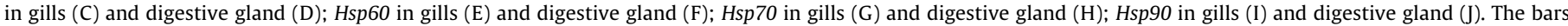

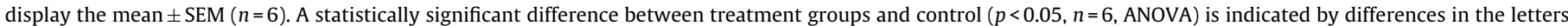
above the bars.

Hsp27 (Benndorf et al., 2001). Hsp40, also known as chaperone DnaJ, is a molecular chaperone protein, which expressed in a wide variety of organisms from bacteria to humans. Hsp40 can protect proteins from irreversible aggregation during synthesis or times of cellular stress, and also play a role in regulating the ATPase activity of Hsp70 (Caplan et al., 1993). We found that exposure to 5 or $50 \mu \mathrm{g} / \mathrm{L}$ CBZ significantly stimulated Hsp22 and Hsp40 mRNA expression in $C$. fluminea gills and digestive gland. This result mirrors a previous study in which we found that Hsp22 and Hsp40 mRNAs expression was stimulated by exposure to 0.5 or $5 \mu \mathrm{g} / \mathrm{L}$ fluoxetine (Chen et al., 2013). Thus, like the biomarker study, the expression levels of $\mathrm{Hsp} 20$ and $\mathrm{Hsp} 40$ indicate that CBZ exposure caused significant stress.

The other three Hsps we evaluated, Hsp60, Hsp70 and Hsp90, are very widely studied and are quite abundant in cells under normal physiological conditions (Feder and Hofmann, 1999; Hull et al., 2013). As such, they are important sentinels of chemical stress. Luchmann et al. (2011) reported that Hsp60 was upregulated and Hsp90 was repressed in the gills and digestive gland of Crassostrea brasiliana oysters after exposure to diesel fuel, with Hsp60 being the most prominent biomarker in gills. Similarly, Hsp90 was down regulated in Tanichthys albonubes by exposure to cadmium (Liu et al., 2012). Herein, the mRNA levels of Hsp90 and Hsp60 were enhanced and repressed, respectively, after CBZ exposure. Similarly, the mRNA levels of $H s p 60, H s p 70$, and $H s p 90$ were enhanced in the digestive gland of $C$. fluminea after 30 days of exposure to fluoxetine (Chen et al., 2013). Thus, the perturbation of the expression of five different Hsp mRNAs indicates that CBZ does cause significant chemical stress.

Among the five Hsps, Hsp70 is often the most prominent and the first to be expressed following environmental assaults (Gupta et al., 2010). Hsp70 mRNA levels were decreased in gills of the zebra mussel $D$. polymorpha after 7 days of exposure to 2.36 , 23.6, or $263 \mu \mathrm{g} / \mathrm{L}$ CBZ (Contardo-Jara et al., 2011), and Del Rey et al. (2011) reported that Hsp70 protein levels in Mytilus californianus gills were initially attenuated and later up-regulated by exposure to 0.2 or $0.5 \mu \mathrm{g} / \mathrm{L}$ caffeine. This result is similar to our findings, in which CBZ exposure up-regulated Hsp70 transcripts levels in $C$. fluminea. Western blotting analysis of Hsp70 protein levels gave results consistent with the increase in mRNA expression. In aggregate, our results confirm that CBZ can exert molecular-level stress on C. fluminea tissues and that Hsp 
Gills
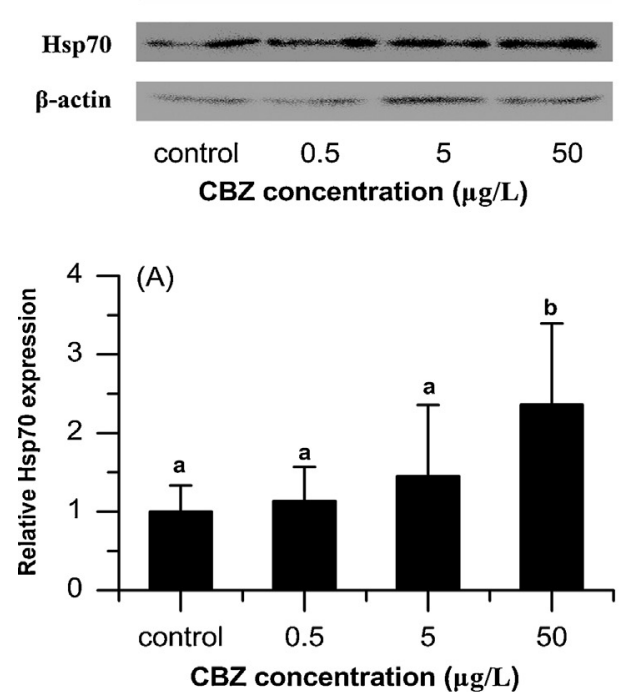

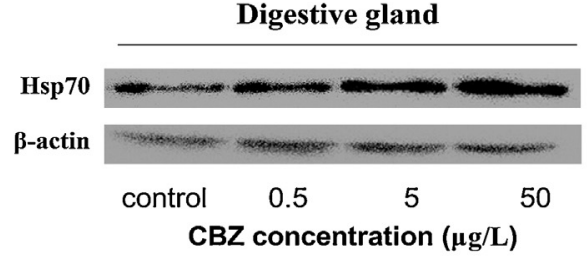

(B)

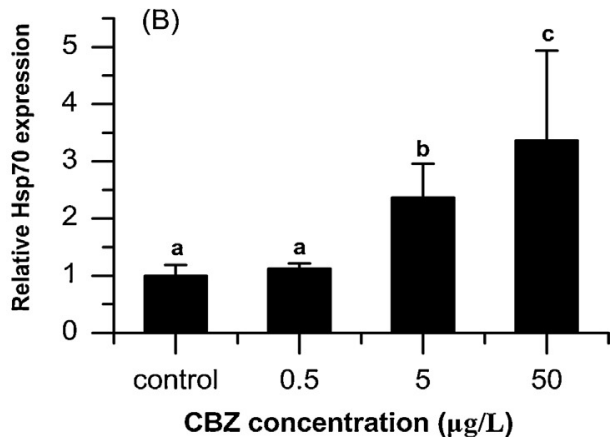

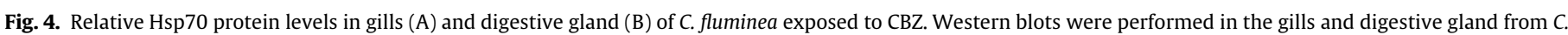

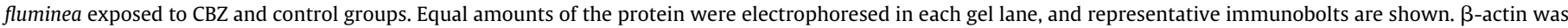

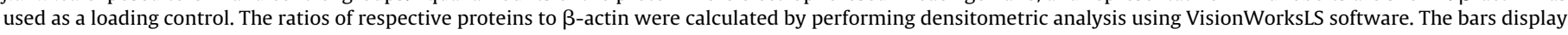

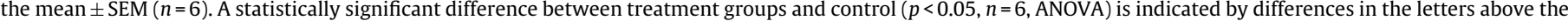
bars.

levels are useful sentinels of the stress caused by environmental contaminants.

\section{Conclusions}

Exposure to environmentally relevant concentrations of CBZ altered the siphoning behavior, biomarkers, and Hsp mRNA and protein levels in the gills and digestive gland of $C$. fluminea. The changes in the biomarkers suggest that the effect of CBZ is related to oxidative stress. Consistent with literature studies, our data indicate that Hsp expression is a useful biomarker of environmental stress. Finally, this study highlights the need for a better understanding of the effects of environmental pharmaceutical contaminants on non-target organisms.

\section{Acknowledgments}

This work was supported by the National Natural Science Foundation of China (21107131) and the National High-tech R\&D Program (2012AA06A302).

\section{References}

Araujo, R., Moreno, D., Ramos, M., 1993. The Asiatic clam Corbicula fluminea (Müller, 1774) (Bivalvia: Corbiculidae) in Europe. Am. Malacol. Bull. 10, 39-49.

Batt, A.L., Kostich, M.S., Lazorchak, J.M., 2008. Analysis of ecologically relevant pharmaceuticals in wastewater and surface water using selective solid-phase extraction and UPLC-MS/MS. Anal. Chem. 80, 5021-5030.

Benndorf, R., Sun, X., Gilmont, R.R., Biederman, K.J., Molloy, M.P., Goodmurphy, C.W., Cheng, H., Andrews, P.C., Welsh, M.J., 2001. Hsp22, a new member of the small heat shock protein superfamily, interacts with mimic of phosphorylated Hsp27 ((3D) Hsp27). J. Biol. Chem. 276, 26753-26761.

Blair, B.D., Crago, J.P., Hedman, C.J., Klaper, R.D., 2013. Pharmaceuticals and personal care products found in the Great Lakes above concentrations of environmental concern. Chemosphere 93, 2116-2123.

Caplan, A., Cyr, D., Douglas, M., 1993. Eukaryotic homologues of Escherichia coli dnaJ: a diverse protein family that functions with hsp70 stress proteins. Mol. Biol. Cell. $4,555$.

Chen, H., Zha, J., Liang, X., Bu, J., Wang, M., Wang, Z., 2013. Sequencing and De Novo assembly of the Asian clam (Corbicula fluminea) transcriptome using the illumina GAIIx method. PLoS One 8, e79516.

Chen, W.Y., Jou, L.J., Chen, S.H., Liao, C.M., 2012. A real-time biomonitoring system to detect arsenic toxicity by valve movement in freshwater clam Corbicula fluminea. Ecotoxicology 21, 1177-1187.
Contardo-Jara, V., Lorenz, C., Pflugmacher, S., Nutzmann, G., Kloas, W., Wiegand, C., 2011. Exposure to human pharmaceuticals Carbamazepine, Ibuprofen and Bezafibrate causes molecular effects in Dreissena polymorpha. Aquat. Toxicol. 105, 428-437.

Cooper, N.L., Bidwell, J.R., 2006. Cholinesterase inhibition and impacts on behavior of the Asian clam, Corbicula fluminea, after exposure to an organophosphate insecticide. Aquat. Toxicol. 76, 258-267.

Daughton, C.G., Ternes, T.A., 1999. Pharmaceuticals and personal care products in the environment: agents of subtle change? Environ. Health Perspect. 107 (Suppl 6), 907-938.

Daughton, C.G., 2014. The Matthew effect and widely prescribed pharmaceuticals lacking environmental monitoring: case study of an exposure-assessment vulnerability. Sci. Total Environ. 466-467, 315-325.

Del Rey, Z.R., Granek, E.F., Buckley, B.A., 2011. Expression of HSP70 in Mytilus californianus following exposure to caffeine. Ecotoxicology 20, 855-861.

Doherty, F.G., Cherry, D.S., Cairns Jr., J., 1987. Valve closure responses of the Asiatic clam Corbicula fluminea exposed to cadmium and zinc. Hydrobiologia 153, 159-167.

Feder, M.E., Hofmann, G.E., 1999. Heat-shock proteins, molecular chaperones, and the stress response: evolutionary and ecological physiology. Ann. Rev. Physiol. $61,243-282$.

Fent, K., Weston, A.A., Caminada, D., 2006. Ecotoxicology of human pharmaceuticals. Aquat. Toxicol. 76, 122-159.

Ferrari, B., Mons, R., Vollat, B., Fraysse, B., Paxeus, N., Lo Giudice, R., Pollio, A., Garric, J., 2004. Environmental risk assessment of six human pharmaceuticals: are the current environmental risk assessment procedures sufficient for the protection of the aquatic environment? Environ. Toxicol. Chem. 23, 1344-1354.

Ferrer, I., Thurman, E.M., 2012. Analysis of 100 pharmaceuticals and their degradates in water samples by liquid chromatography/quadrupole time-of-flight mass spectrometry. J. Chromatogr. A 1259, 148-157.

García-Morales, I., Rieger, J.S., Gil-Nagel, A., Fernández, J.L.H., 2007. Antiepileptic drugs: from scientific evidence to clinical practice. Neurologist 13, S20-S28.

Gonzalez-Rey, M., Bebianno, M.J., 2013. Does selective serotonin reuptake inhibitor (SSRI) fluoxetine affects mussel Mytilus galloprovincialis? Environ. Pollut. 173, 200-209.

Gupta, S.C., Sharma, A., Mishra, M., Mishra, R.K., Chowdhuri, D.K., 2010. Heat shock proteins in toxicology: how close and how far? Life Sci. 86, 377-384.

Hull, J.J., Geib, S.M., Fabrick, J.A., Brent, C.S., 2013. Sequencing and de novo assembly of the western tarnished plant bug (Lygus hesperus) transcriptome. PLoS One 8 , e55105.

Kim, Y., Choi, K., Jung, J., Park, S., Kim, P.-G., Park, J., 2007. Aquatic toxicity of acetaminophen, carbamazepine, cimetidine, diltiazem and six major sulfonamides, and their potential ecological risks in Korea. Environ. Int. 33, $370-375$.

Kim, R.O., Rhee, J.S., Won, E.J., Lee, K.W., Kang, C.M., Lee, Y.M., Lee, J.S., 2011. Ultraviolet $\mathrm{B}$ retards growth, induces oxidative stress, and modulates DNA repair-related gene and heat shock protein gene expression in the monogonont rotifer, $\mathrm{Bra}$ chionus sp. Aquat. Toxicol. 101, 529-539.

Koehler, A., 2004. The gender-specific risk to liver toxicity and cancer of flounder (Platichthys flesus (L.)) at the German Wadden Sea coast. Aquat. Toxicol. 70, 257-276. 
Liu, H., Chen, H., Jing. J., Ma, X., 2012. Cloning and characterization of the HSP90 beta gene from Tanichthys albonubes Lin (Cyprinidae): effect of copper and cadmium exposure. Fish Physiol. Biochem. 38, 745-756.

Liu, J.L., Wong, M.H., 2013. Pharmaceuticals and personal care products (PPCPs): a review on environmental contamination in China. Environ. Int. 59C, 208-224.

Luchmann, K.H., Mattos, J.J., Siebert, M.N., Granucci, N., Dorrington, T.S., Bicego, M.C., Taniguchi, S., Sasaki, S.T., Daura-Jorge, F.G., Bainy, A.C., 2011. Biochemical biomarkers and hydrocarbons concentrations in the mangrove oyster Crassostrea brasiliana following exposure to diesel fuel water-accommodated fraction. Aquat. Toxicol. 105, 652-660.

Lushchak, V.I., 2011. Environmentally induced oxidative stress in aquatic animals. Aquat. Toxicol. 101, 13-30.

Marnett, L.J., 1999. Lipid peroxidation-DNA damage by malondialdehyde. Mutat. Res. 424, 83-95.

Martin-Diaz, L., Franzellitti, S., Buratti, S., Valbonesi, P., Capuzzo, A., Fabbri, E., 2009 Effects of environmental concentrations of the antiepilectic drug carbamazepine on biomarkers and cAMP-mediated cell signaling in the mussel Mytilus galloprovincialis. Aquat. Toxicol. 94, 177-185.

McCord, J.M., Fridovich, I., 1969. Superoxide dismutase an enzymic function for erythrocuprein (hemocuprein). J. Biol. Chem. 244, 6049-6055.

Milam, C.D., Farris, J.L., 1998. Risk identification associated with iron-dominated mine discharges and their effect upon freshwater bivalves. Environ. Toxicol. Chem. 17, 1611-1619.

Moulton, C.A., Fleming, W.J., Purnell, C.E., 1996. Effects of two cholinesteraseinhibiting pesticides on freshwater mussels. Environ. Toxicol. Chem. 15, $131-137$.
Ren, J., Luo, J., Ma, H., Wang, X., Ma, L.Q., 2013. Bioavailability and oxidative stress of cadmium to Corbicula fluminea. ESPI 15, 860-869.

Santoro, M.G., 2000. Heat shock factors and the control of the stress response. Biochem. Pharmacol. 59, 55-63.

Schmittgen, T.D., Livak, K.J., 2008. Analyzing real-time PCR data by the comparative C(T) method. Nat. Protoc. 3, 1101-1108.

Sørensen, J.G., Kristensen, T.N., Loeschcke, V., 2003. The evolutionary and ecological role of heat shock proteins. Ecol. Lett. 6, 1025-1037.

Stancliffe, R.A., Thorpe, T., Zemel, M.B., 2011. Dairy attentuates oxidative and inflammatory stress in metabolic syndrome. Am. J. Clin. Nutr. 94, 422-430.

Tsiaka, P., Tsarpali, V., Ntaikou, I., Kostopoulou, M.N., Lyberatos, G., Dailianis, S., 2013. Carbamazepine-mediated pro-oxidant effects on the unicellular marine algal species Dunaliella tertiolecta and the hemocytes of mussel Mytilus galloprovincialis. Ecotoxicology 22, 1208-1220.

Vasconcelos, V., Martins, J.C., Leao, P.N., 2009. Differential protein expression in Cor bicula fluminea upon exposure to a Microcystis aeruginosa toxic strain. Toxicon $53,409-416$.

Verlecar, X., Jena, K., Chainy, G., 2008. Modulation of antioxidant defences in digestive gland of Perna viridis (L.), on mercury exposures. Chemosphere 71, 1977-1985.

Zhang, Y., Geissen, S.U., Gal, C., 2008. Carbamazepine and diclofenac: removal in wastewater treatment plants and occurrence in water bodies. Chemosphere 73 , 1151-1161

Zhang, Z., Zhang, Q., 2012. Molecular cloning, characterization and expression of heat shock protein 70 gene from the oyster Crassostrea hongkongensis responding to thermal stress and exposure of $\mathrm{Cu}\left(2^{+}\right)$and malachite green. Gene 497, 172-180. 